\title{
Energy-saving drying technology for porous media using liquefied DME gas
}

\author{
Hideki Kanda · Hisao Makino • Minoru Miyahara
}

Received: 15 June 2007 / Revised: 25 December 2007 / Accepted: 28 March 2008 / Published online: 23 April 2008

(C) The Author(s) 2008. This article is published with open access at Springerlink.com

\begin{abstract}
Process design and energy requirement for a practical plant are investigated for an energy-saving drying (dewatering) process invented by the authors in 2002 for highmoisture porous materials. The basic concept of the process involves the extraction of water from a high-moisture porous material by bringing it in physical contact with liquefied dimethyl ether (DME) at room temperature. Water content of DME asymptotically increases to the saturation value and the high-moisture porous material is dried almost perfectly. DME from the DME-water mixture is vaporized by decompression. DME and water are separated by flash distillation. DME vapor is compressed and cooled in a heat exchanger, and the latent heat of condensation is reused to vaporize the DME in the heat exchanger. Multistage compression and multistage flash distillation are employed. After compression, the temperature of DME is less than $50^{\circ} \mathrm{C}$. Because specific heat ratio of DME is only 1.11 , the energy consumption of the compressor is reduced. Considering the adiabatic efficiency of the compressor and the net thermal efficiency, the total energy for dewatering is about $1100 \mathrm{~kJ}$ per 1-kg-water-content of the material being dewatered This process has significant potential and is compact than the existing dewatering processes.
\end{abstract}

Keywords High moisture coal · Dewatering - Dimethyl ether · Process design - Energy requirement

\section{H. Kanda $(\varangle) \cdot$ H. Makino}

Energy Engineering Research Laboratory, Central Research Institute of Electric Power Industry, Kanagawa 240-0196, Japan e-mail: kanda@criepi.denken.or.jp

M. Miyahara

Chemical Engineering Department, Kyoto University,

Kyoto 615-8510, Japan

\section{Introduction}

The high-moisture coal (sub-bituminous coal and lignite) is the largest in the porous material. The sub-bituminous coal and lignite account for $40 \%$ of all recoverable coal. The high moisture content of coal results from its strong capacity to adsorb water; this makes drying difficult. Since a high moisture content is undesirable from the perspective of transportation and power generation efficiency, Australian (Victorian) brown coal, for example, is consumed by electrical power stations that are located close to the coal mine. Before the coal is loaded into a combustion furnace, it must be dewatered (dried). A Victorian furnace requires about 3 times the cubic volume of typical Japanese furnaces. As a result, the power generation efficiency of Victorian power plant is lower than $30 \%$; this increases the $\mathrm{CO}_{2}$ emissions.

The authors have invented an efficient process for the dewatering of high moisture content coal. This process utilizes lesser energy than that required by the existing technology under normal temperature and non-thermal conditions (Kanda and Shirai 2002). A number of different dewatering techniques have been investigated in the previous researches. However, as demonstrated by Miura et al. (2002), the current dewatering techniques consume considerable energy or require costly chemicals. Classical techniques involving high energy consumption include dewatering using supercritical $\mathrm{CO}_{2}$ (Iwai et al. 1998) as well as the following methods: flash dry, steam tube drying (STD), steam fluidized bed drying (SFBD), mechanical thermal expression (MTE), hydrothermal drying (HTD), the Koppelman process (Kfuel) (Couch 1990), upgraded of brown coal method (UBC) (Simmons 1986; Okuma et al., 1986, 1989a, 1989b; Yanagi et al. 1994; Deguchi et al. 1996; Terunuma et al. 1986; Yosumuro et al. 2000; Shigehisa et al. 2000), the Syncoal technique (U.S. DOE 1996), hot water dewatering (HWD) 
(Anderson et al. 1990), and the Encoal technique (U.S. DOE 1997).

Among these processes, the UBC process is the most practical one because of a 600 ton/d processing capacity pilot plant being constructed in Indonesia. In the UBC process, coal is dewatered by using oil to heat slurried coal to about $150-200{ }^{\circ} \mathrm{C}$. The oil includes asphalt and other heavy oils that are adsorbed by the dewatered coal, thus suppressing spontaneous combustion and rewetting. However, the UBC process also uses a bricket technique that significantly relies on unstable coal; therefore, its effectiveness remains unclear. Nevertheless, its advantage is that the use of oil as the heat medium significantly increases the heat conductivity of coal and compresses the water vapor generated to raise the saturation temperature. When this water vapor condenses at a high temperature, it generates latent heat of condensation in a high temperature range, which is then reused as a source of heat. However, since the oil (used as the heat medium) has a higher boiling point than water, extracting coal from oil requires oil separation and evaporation by means of centrifugal separation and drying at temperatures exceeding the evaporation temperature of water. Consequently, a considerable amount of heat energy is required to achieve this; this is a major drawback of the UBC method.

\section{Basic concept and design of DME dewatering process}

Considering the above aspects of the UBC process, the authors (Kanda and Shirai 2002) formulated the concept of a new dewatering process that extracts water content from coal using liquefied dimethyl ether (DME). The process is called DME dewaterization, for which we performed trial calculations. The main characteristic of the DME dewatering process is the use of DME. DME is a combustible gas similar to propane and butane; however, unlike these two fuels, it binds water molecules to its hydrogen atoms, which gives it the capacity to merge with the water content of the coal. In particular, DME is being mass produced in China as a raw material for coal gasification as the country lacks liquefied fuel. More efficient DME production implies that a DME plant can produce more than several hundred tons of DME annually. Though not confirmed, information indicates that a DME pipeline is being constructed from Inner Mongolia to Beijing and Shanghai. At US $\$ 200$ per ton, DME is cheaper, both in terms of calorie base and weight base, than US\$500 per ton liquefied petroleum gas (approximately double the calories per weight). This, along with the rush of Western and local firms to set up DME plants to meet the sharply rising energy demand in recent years, has contributed to the intense interest in DME.

This process uses DME because its physical properties make it the most suitable water extractant. The normal boiling point of DME is $-24.8{ }^{\circ} \mathrm{C}$, and at $0.59 \mathrm{MPa}$, it is $25^{\circ} \mathrm{C}$.

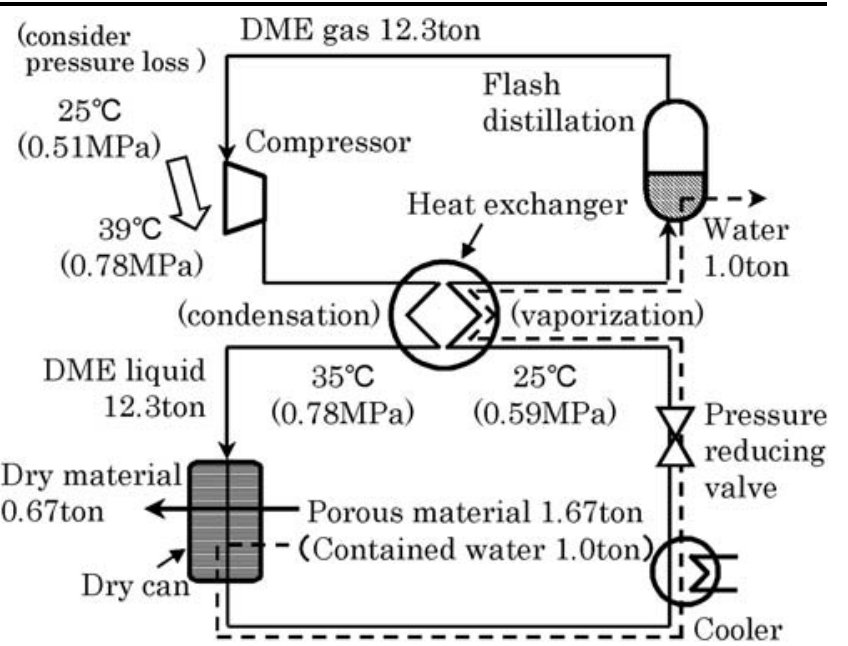

Fig. 1 Basic and ideal DME dewatering process

At normal ambient temperature, DME dissolves $7-8 \%$ by weight of water (Holldorff and Knapp 1988). Moreover, the ratio of the specific heats, $\gamma=C_{\mathrm{P}} / C_{\mathrm{V}}$, of DME at normal temperature is approximately 1.1-1.2, and the energy released from compression does not increase the temperature; in fact, the energy is mostly expended for increasing the pressure. Consequently, DME is can be compressed very easily. Furthermore, it does not contain metals, halogen, nitrogen, sulfur, and other environmentally harmful elements. Originally, used mainly as a fuel, DME can be safely burned along with coal after dewatering.

Using this characteristic of DME, as shown in Fig. 1, in a dewatering bin under normal temperature coal is brought into contact with liquefied DME. After extracting moisture from the coal, the DME containing water passes through a decompression valve and is flash distilled to separate the liquid waste water from the DME gas. The DME gas is then collected, and its temperature and pressure are raised in a compressor. It is then condensed and reused. The latent heat generated during condensation is collected for use as a heat source for the flash evaporation part of the process.

In Fig. 1, the mixture of water and liquefied DME is evaporated using the latent heat of condensation of DME gas. The minimum temperature difference between the evaporation and condensation tubes in the heat exchanger (approach temperature) is $10^{\circ} \mathrm{C}$. Here, a large temperature difference implies a smaller heat exchanger and thus lower equipment cost; however, this also lowers evaporation pressure, thus increasing the load on the compressor. On the other hand, setting the temperature difference to less than $10^{\circ} \mathrm{C}$ considerably increases the size and cost of heat exchanger; therefore, the minimum temperature difference has been set at $10^{\circ} \mathrm{C}$. 
Fig. 2 Process configuration of improved DME dewatering process

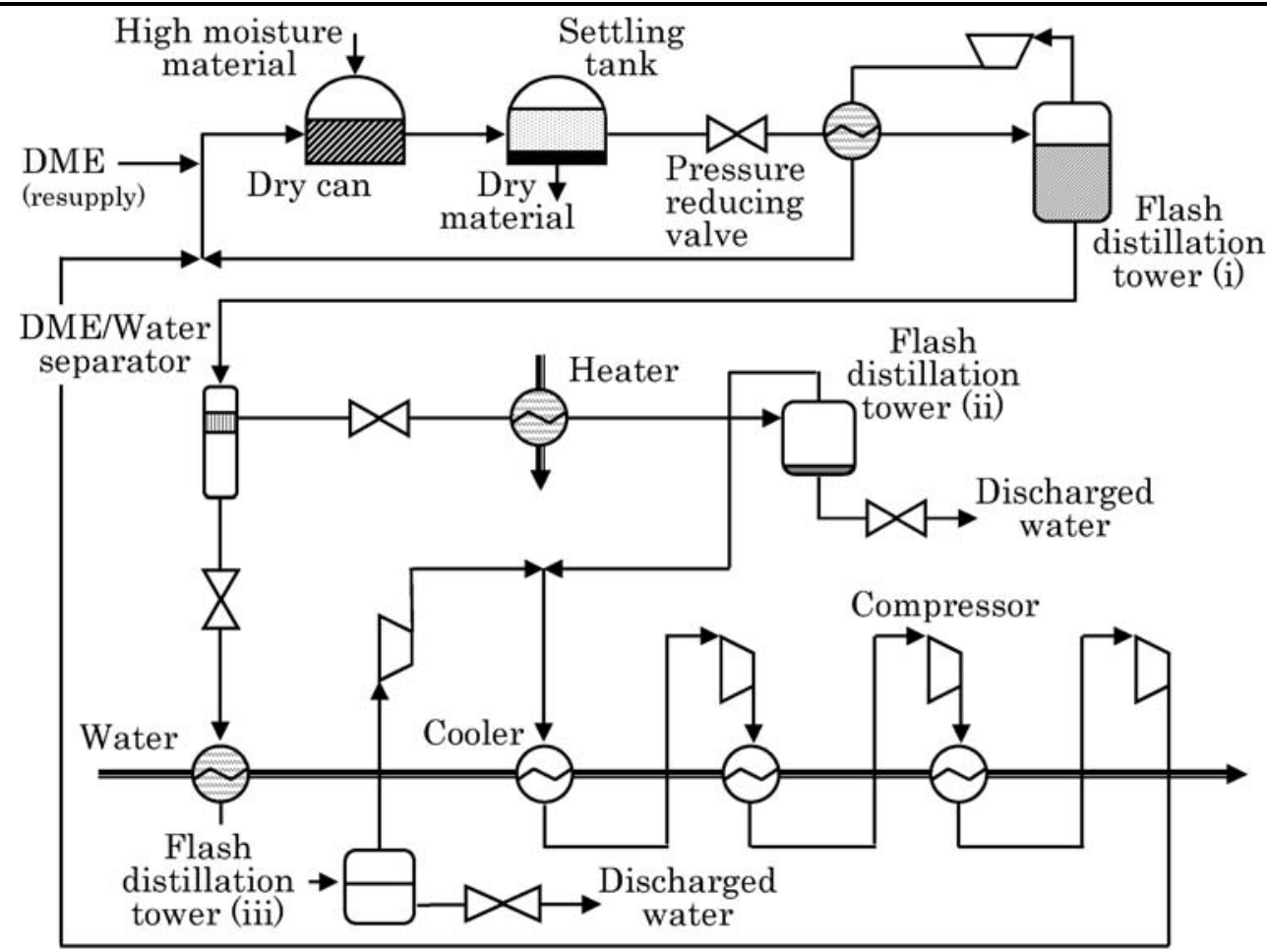

\section{Plant design of DME dewatering process}

In this section, we provide a detailed framework of DME dewatering process. The framework resembles the actual equipment. Our aim is to construct a large-scale DME dewatering plant and confirm energy required for dewatering and the criteria necessary for evaluating the feasibility of actual production equipment.

In the previous section, we discussed why DME is best suited to dewater. However, we did not consider the temperature dependent factors: specific heat and latent heat of evaporation in the basic design of DME dewatering Process.

The Process configuration of the improved DME dewatering process is shown in Fig. 2.

After the liquefied DME was mixed with several $\mathrm{mm}$ to several $\mathrm{cm}$ of crushed high moisture content coal in a dewatering bin, the high moisture content coal is settled in a sedimentation tank. In this process, the water contained in the coal is extracted by the liquefied DME. The techniques for inputting and extracting the high moisture content coal are currently being studied along with the manufacturer and will not be discussed here.

Liquefied DME containing the water extracted from the high moisture content coal is extracted from the top portion of the sedimentation tank, depressurized, and flash distilled in the flash distraction tower (i), (ii) and (iii). The evaporated DME is heated and pressurized in a compressor, and to avoid the wastage of the latent heat of evaporation and temperature loss during flash distillation, the DME is condensed and the latent heat of condensation of higher temperature is used for flash distillation. The condensed liquefied DME is then returned to the system and reused

However, as stated above, the surplus liquefied DME is extracted from the bottom of the flash distillation tower (i). It is strongly saturated with water, and specific gravity separation of the phases occurs: DME-rich phase at the top and a water-rich phase at the bottom. The phase splitting is performed using a tall oily water separator that is long and narrow.

Only the DME-rich layer is extracted from the top of the oily water separator and flash distilled. Since, as stated above, the DME extracted comprises only a very small portion of the total amount. An external heat supply, in the form of external water heat exchange, is used for the DME evaporator. The water from this flash distillation tower (ii) is discarded.

Only the water-rich layer is extracted from the lower part of the oily water separator and flash distilled. The water from this flash distillation tower (iii) is discarded. After evaporating, this DME is compressed and reused. Since the DME pressure drops sharply during this process, multi-stage compression is used to reduce energy consumption.

We first focused on the fact that when the DME gas that evaporates from the DME/water separator is heated, pressurized, and subsequently condensed in a cooler, the latent heat generated is less than the latent heat that the water separator requires for evaporation. Generally, the higher the temperature, the lesser is the condensation (evaporation) latent 
heat. Since unevaporated DME contains water, its latent heat of evaporation is greater than that of pure DME. Therefore an external heat supply, in the form of external air and water heat exchange, is used for the DME evaporator. Consequently, it is necessary to leave part of the liquefied DME unevaporated and add a process for collecting it. However, the presence of unevaporated liquefied DME requires a further reduction in pressure followed by compression from the lowered pressure. This causes more power consumption for the compressor relative to the amount of DME collected. Therefore, in order to reduce the energy consumption, the liquefied DME is evaporated at multiple points using compressors in a multi-stage set up.

Moreover, as shown in Fig. 1, DME dewatering requires a condenser. This is because the workload input into the process system by the compressor is greater than the workload for extracting water from coal. The evaporation process to collect the unevaporated liquefied DME and condensation are achieved by using an external heat supplied by external water (temperature: $25^{\circ} \mathrm{C}$ ). This is done for the following reasons. First, it is assumed that the unevaporated liquefied DME comprises only a small amount of the total DME in the system. Second, additional costs are incurred by installing a small DME heat exchanger.

The heat exchanger of the main evaporator involves the greatest amount of heat transfer, so a significant heat loss occurs at this point. Moreover, the DME dewatering process is essentially a repeating loop, and calculating mass balance and heat balance, which will be discussed later, requires a convergence calculation. Therefore, we carried out a convergence calculation as a parameter adjustment for the heat loss that occurs at this point in the process.

\section{Energy required for the DME dewatering process}

We assumed a processing volume of 114 tons per day of coal (66.7 weight $\%$ of water content), as approximating actual scale with real equipment, and calculated the temperature, pressure, and flow rate for steady operation conditions. More specifically, we set up a mass balance equation for the temperature, pressure, and flow rate functions and a heat balance equation for heat convergence. We performed a heat convergence calculation for the recycling loop to adjust heat loss parameters for the heat exchanger of the flash distillation tower (i). We defined the ratio of vapor from the saturation vapor pressure, temperature and input energy. The software was our original convergence routine with tables of thermodynamic properties of DME and water to clarify ideal power consumption in steady state.

We used the loss of the heat exchanger as an adjustment parameter to convergent, convergence routine that corrects the adjustment parameter is added. As a result, we ultimately performed a two-fold convergence calculation.
Moreover, we set a binding condition of less than $50{ }^{\circ} \mathrm{C}$ for the maximum temperature within the process. We set DME loss for the entire cycle at $1 \%$. This provisional value was set because high DME loss increases the operation costs of the dewatering process, while a low DME loss increased the costs of the DME synthetic processing. We set the heat exchanger approach temperature at $10^{\circ} \mathrm{C}$.

The results of calculations based on the above criteria follow.

\subsection{Operation temperature and pressure of the DME dewatering process}

Figure 3 and Table 1 show the values of temperature and pressure for the improved DME dewatering process under steady operation conditions. Most of the DME is evaporated at $25^{\circ} \mathrm{C}$ in the flash distillation tower (i), pressurized to $45^{\circ} \mathrm{C}$ and $0.78 \mathrm{MPa}$ in the compressor, and then its latent heat of condensation is released at $36^{\circ} \mathrm{C}$. This heat is collected to supply the latent heat of evaporation during flash distillation.

Surplus DME is under mild conditions: $25^{\circ} \mathrm{C}$ and $0.53 \mathrm{MPa}$, respectively. Collecting this DME requires flash distillation at a still lower temperature and pressure. Specifically, to collect the DME, the temperature and pressure for flash distillation tower (ii) need to be $15^{\circ} \mathrm{C}$ and $0.32 \mathrm{MPa}$, respectively, and for flash distillation tower (iii), $15^{\circ} \mathrm{C}$ and $0.16 \mathrm{MPa}$, respectively.

The evaporated DME is repeatedly cooled by multi-stage compression and using external water; the multi-stage compression lowers temperature to a range below $50^{\circ} \mathrm{C}$ and raises pressure to $0.78 \mathrm{MPa}$; subsequently, the DME is collected.

\subsection{Mass and heat balance of the DME dewatering process}

Figure 3 and Table 1 show the mass balance for the improved DME dewatering process under steady operation conditions. In flash distillation tower (i), $95.2 \%$ of the total DME can be collected. As regards the uncollected $4.8 \%$, the shape of the oily water separator should be modified so that it can process approximately 5 ton/d of DME-rich and 116 ton/d of water-rich liquid phases. Collecting DME from the DMErich phase is relatively easy because it is a small amount of liquid with a high DME content. On the other hand, the water-rich phase is a large amount of liquid containing up to about $35 \%$ soluble DME, which greatly increase the workload of flash distillation tower (iii). Moreover, most of the DME is lost through the waste water discharge opening of this tower.

Table 1 also shows the heat balance and compression motive power for the improved DME dewatering process under steady operation conditions. A significant amount of latent 


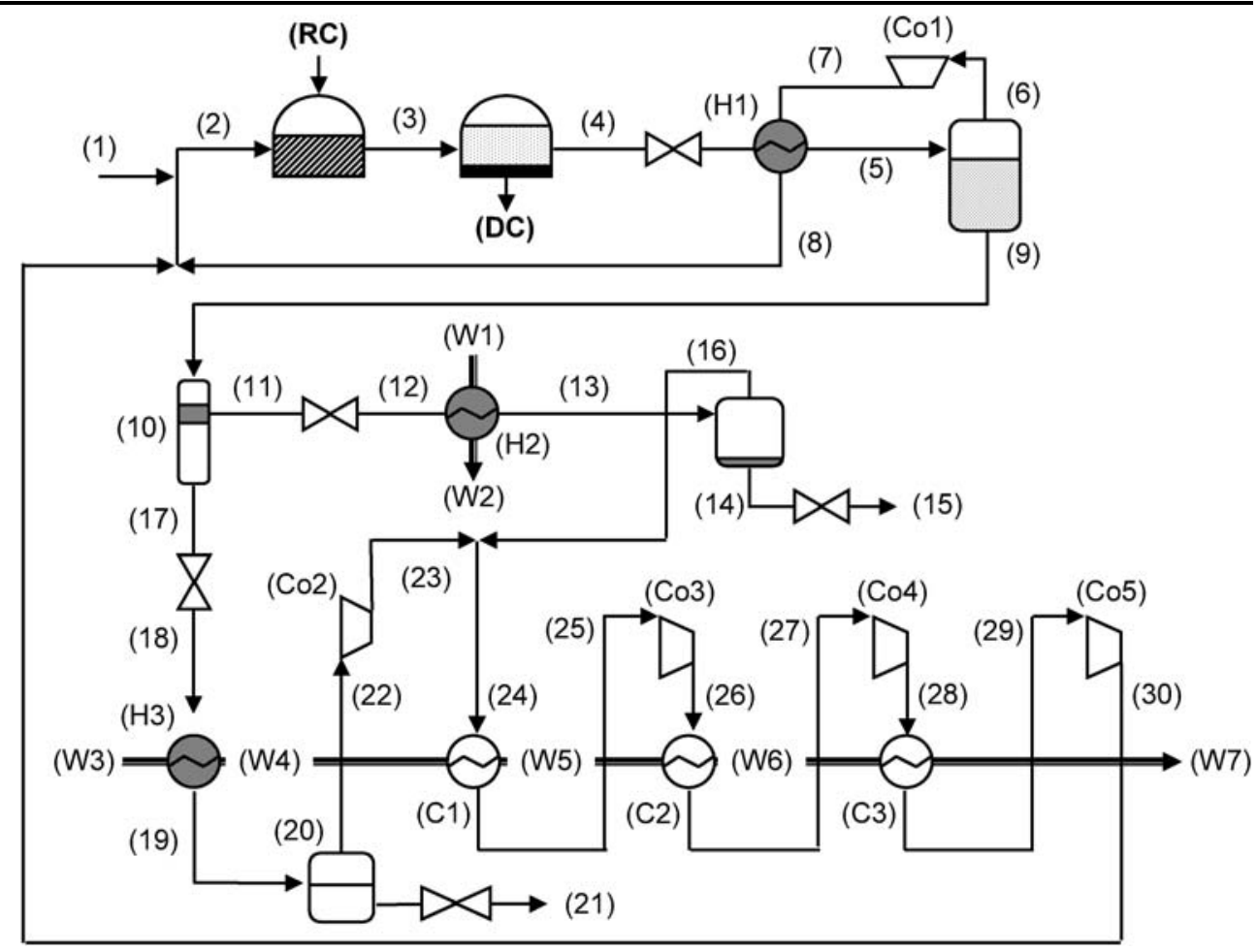

heat is lost in heat exchanger $\mathrm{H} 1$; nevertheless, in terms of establishing a DME dewatering process, this process proves to be thermally superior. Besides compressor Co1 and heat exchanger $\mathrm{H} 1$, heat transfer between the other compressors and heat exchangers is relatively small and therefore insignificant. We calculated the polytropic efficiency of the compressor using the values of temperature and pressure at the compressor's input and output. The calculated polytropic efficiency was $75-76 \%$ as shown in Table 1 , so we considered the compressors' adiabatic efficiency as 0.75 .

\subsection{Energy requirement of the DME dewatering process}

In Table 1 , the total waste water generated by flow numbers [15] and [21] is 76.01 ton/d; the total energy flow, summed from [Co1] to [Co5], is $29497 \mathrm{MJ} / \mathrm{d}$; and the power generation efficiency is calculated to be 0.35 . (The equation is as follows: $29497 \mathrm{MJ} / \mathrm{d} /(76.01 \times 1000) \mathrm{kg} / \mathrm{d} / 0.35$. $)$ This gives a dewatering energy sum for this process of $1109 \mathrm{~kJ} / \mathrm{kg}$-water. This value matches well with the previous results (Kanda and Shirai 2002), confirming that this modified DME dewatering process is much more efficient than the existing dewatering processes.

\section{Conclusion}

We studied the design of a DME dewatering process for which the process energy consumption was calculated con- sidering a real a scale DME processing plant.

We considered the fact that when DME gas evaporated in a water separator is heated, pressurized, and subsequently condensed, the generated latent heat of condensation is lower than the latent heat of evaporation needed for the water separator to cause evaporation. Further, we considered the heat loss in heat exchanger, causing surplus unevaporated liquefied DME that is required to be collected by a separate process.

For calculating the mass balance, heat balance, and heat exchanger related heat loss for the process, we assumed an internal maximum temperature of less than $50^{\circ} \mathrm{C}$ and DME loss of $1 \%$, respectively. Based on these criteria, we set up an equation to perform a convergence calculation.

We determined the process design based on actual largescale processing of 114 ton/d of $66.7 \%$-water-content coal. The results indicated that although $4 \%$ of the DME remains unevaporated in the first flash distillation, the remaining DME can be collected for reuse using an external heat supply, in the form of external water (temperature: $25^{\circ} \mathrm{C}$ ) heat exchange. The energy requirement of the DME dewatering process was calculated from that of the compressors. It is established that the process can dewater DME at approximately $1100 \mathrm{~kJ} / \mathrm{kg}$-water.

Now, based on these results, we plan to develop a DME dewatering process that approximates large-scale processing with actual equipment. 


\begin{tabular}{|c|c|c|c|c|c|c|c|c|c|c|}
\hline \multirow{2}{*}{$\begin{array}{l}\text { Flow } \\
\text { No. }\end{array}$} & \multirow{2}{*}{$\begin{array}{l}\text { Temperature } \\
\left({ }^{\circ} \mathrm{C}\right)\end{array}$} & \multirow{2}{*}{$\begin{array}{l}\text { Pressure } \\
(\mathrm{MPa})\end{array}$} & \multirow{2}{*}{$\begin{array}{l}\text { Ratio of } \\
\text { vapor } \\
(-)\end{array}$} & \multicolumn{4}{|l|}{ Flow rate } & \multirow{2}{*}{$\begin{array}{l}\text { Energy } \\
\text { flow } \\
(\mathrm{MJ} / \mathrm{d})\end{array}$} & \multirow{2}{*}{$\begin{array}{l}\text { Remarks in } \\
\text { energy flow }\end{array}$} & \multirow{2}{*}{$\begin{array}{l}\text { Compressor, } \\
\text { heater and } \\
\text { cooler No. }\end{array}$} \\
\hline & & & & Total & $\begin{array}{l}\text { Water } \\
\text { (ton } / \mathrm{d} \text { ) }\end{array}$ & DME & $\begin{array}{l}\text { Total } \\
\left(\mathrm{m}^{3} / \mathrm{d}\right)\end{array}$ & & & \\
\hline 1 & 25.00 & 0.78 & 0.00 & 8.88 & 0.04 & 8.84 & 13.23 & 0 & Against (21) & \\
\hline 2 & 35.57 & 0.78 & 0.05 & 937.98 & 2.06 & 935.92 & $1,398.33$ & & & \\
\hline $\mathrm{RC}$ & 25.00 & 0.78 & 0.00 & 75.97 & 75.97 & 0.00 & 76.12 & 3,448 & Against (21) & \\
\hline 3 & 39.71 & 0.78 & 0.01 & $1,013.95$ & 78.03 & 935.92 & $1,474.45$ & & & \\
\hline DC & 39.71 & 0.78 & \multicolumn{5}{|c|}{ Dry coal (out of consideration of sensible heat) } & 0 & & \\
\hline 4 & 39.71 & 0.78 & 0.01 & $1,013.95$ & 78.03 & 935.92 & $1,474.45$ & & & \\
\hline 5 & 25.20 & 0.53 & 0.79 & $1,013.95$ & 78.03 & 935.92 & $1,474.45$ & 336,914 & & $\mathrm{H} 1$ \\
\hline 6 & 25.20 & 0.53 & 1.00 & 892.65 & 1.88 & 890.77 & $1,330.80$ & & & \\
\hline 7 & 44.73 & 0.78 & 1.00 & 892.65 & 1.88 & 890.77 & $1,330.80$ & 25,459 & & Co1 \\
\hline 8 & 35.55 & 0.78 & 0.01 & 892.65 & 1.88 & 890.77 & $1,330.80$ & $-379,068$ & & $\mathrm{H} 1$ \\
\hline 9 & 25.20 & 0.53 & 0.00 & 121.30 & 76.15 & 45.15 & 143.66 & & & \\
\hline 10 & 25.20 & 0.53 & 0.00 & 121.30 & 76.15 & 45.15 & 143.66 & & & \\
\hline 11 & 25.20 & 0.53 & 0.00 & 5.03 & 0.35 & 4.68 & 7.33 & & & \\
\hline 12 & 8.35 & 0.32 & 0.09 & 5.03 & 0.35 & 4.68 & 7.33 & & & \\
\hline 13 & 15.00 & 0.32 & 0.82 & 5.03 & 0.35 & 4.68 & 7.33 & 1,854 & & $\mathrm{H} 2$ \\
\hline 14 & 15.00 & 0.32 & 0.00 & 0.46 & 0.34 & 0.11 & 0.51 & & & \\
\hline 15 & 8.62 & 0.10 & 0.09 & 0.46 & 0.34 & 0.11 & 0.51 & 0 & Against (21) & \\
\hline 16 & 15.00 & 0.32 & 1.00 & 4.57 & 0.01 & 4.57 & 6.82 & & & \\
\hline 17 & 25.20 & 0.53 & 0.00 & 116.27 & 75.80 & 40.47 & 136.33 & & & \\
\hline 18 & 1.11 & 0.16 & 0.10 & 116.27 & 75.80 & 40.47 & 136.33 & & & \\
\hline 19 & 15.00 & 0.16 & 0.14 & 116.27 & 75.80 & 40.47 & 136.33 & 9,700 & & H3 \\
\hline 20 & 15.00 & 0.16 & 0.00 & 84.39 & 75.67 & 8.72 & 88.84 & & & \\
\hline 21 & 11.26 & 0.10 & 0.01 & 84.39 & 75.67 & 8.72 & 88.84 & 0 & Reference & \\
\hline 22 & 15.00 & 0.16 & 1.00 & 31.87 & 0.13 & 31.75 & 47.49 & & & \\
\hline 23 & 49.81 & 0.32 & 1.00 & 31.87 & 0.13 & 31.75 & 47.49 & 1,612 & & $\mathrm{Co} 2$ \\
\hline 24 & 45.58 & 0.32 & 1.00 & 36.45 & 0.14 & 36.31 & 54.31 & & & \\
\hline 25 & 24.00 & 0.32 & 1.00 & 36.45 & 0.14 & 36.31 & 54.31 & $-1,177$ & & $\mathrm{C} 1$ \\
\hline 26 & 49.79 & 0.54 & 1.00 & 36.45 & 0.14 & 36.31 & 54.31 & 1,408 & & $\mathrm{Co} 3$ \\
\hline 27 & 35.00 & 0.54 & 1.00 & 36.45 & 0.14 & 36.31 & 54.3 & -800 & & $\mathrm{C} 2$ \\
\hline 28 & 46.79 & 0.68 & 1.00 & 36.45 & 0.14 & 36.31 & 54.31 & 636 & & $\mathrm{Co} 4$ \\
\hline 29 & 40.00 & 0.68 & 1.00 & 36.45 & 0.14 & 36.31 & 54.31 & -368 & & $\mathrm{C} 3$ \\
\hline 30 & 47.05 & 0.78 & 1.00 & 36.45 & 0.14 & 36.31 & 54.31 & 382 & & Co5 \\
\hline Wl & 25.0 & 0.10 & 0.00 & 93.07 & 93.07 & 0.00 & 93.07 & & & \\
\hline W2 & 20.3 & 0.10 & 0.00 & 93.07 & 93.07 & 0.00 & 93.07 & $-1,854$ & & $\mathrm{H} 2$ \\
\hline W3 & 25.0 & 0.10 & 0.00 & 167.61 & 167.61 & 0.00 & 167.61 & & & \\
\hline W4 & 11.2 & 0.10 & 0.00 & 167.61 & 167.61 & 0.00 & 167.61 & $-9,700$ & & H3 \\
\hline W5 & 12.9 & 0.10 & 0.00 & 167.61 & 167.61 & 0.00 & 167.61 & 1,177 & & $\mathrm{C} 1$ \\
\hline W6 & 14.0 & 0.10 & 0.00 & 167.61 & 167.61 & 0.00 & 167.61 & 800 & & $\mathrm{C} 2$ \\
\hline W7 & 14.6 & 0.10 & 0.00 & 167.61 & 167.61 & 0.00 & 167.61 & 368 & & $\mathrm{C} 3$ \\
\hline
\end{tabular}

Open Access This article is distributed under the terms of the Creative Commons Attribution Noncommercial License which permits any noncommercial use, distribution, and reproduction in any medium, provided the original author(s) and source are credited.

\section{References}

Anderson, B., Johnson, T.R., Mclntosh, M.: In: Int. Coal Eng. Conf., pp. 253-258 (1990) 
Couch, G.R.: In: Lignite Upgrading. IEACR, p. 25 (1990)

Deguchi, T., Shigehisa, T., Katsushima, S., Nakanishi, R., Shimizu, T., Okuma, O.: In: Proceedings of 7th Australian Coal Sci. Conf., pp. 479-485 (1996)

Holldorff, H., Knapp, H.: Fluid Phase Equilib. 44, 195-209 (1988)

Iwai, Y., Amiya, M., Murozono, T., Arai, Y., Sakanishi, K.: Ind. Eng. Chem. Res. 37, 2893-2896 (1998)

Kanda, H., Shirai, H.: Patent pending (2002)

Miura, K., Mae, K., Ashida, R., Tamura, T., Ihara, T.: Fuel 81, 1417 $1422(2002)$

Okuma, O., Mae, K., Nakako, Y.: In: World Congr. III Chem. Eng., vol. 1, pp. 457-460 (1986)

Okuma, O., Mae, K., Hirano, T., Nakako, Y.: Fuel Process. Technol. 23, 117-132 (1989a)

Okuma, O., Mae, K., Yanai, S., Nakako, Y.: Fuel Process. Technol. 22, $73-86$ (1989b)
Shigehisa, T., Deguchi, T., Shimasaki, K., Makino, E.: In: Proceedings of Int. Conf. Fluid and Therm. Energy Conv. (FTEC) 2000, pp. $175-179(2000)$

Simmons, J.J.: U.S. Patent 4,705,533, registered in 1987, filed in 1986

Terunuma, K., Nakako, Y., Matsumura, T.: In: World Congr. III Chem. Eng., vol. 1, pp. 73-76 (1986)

U.S. DOE: Clean coal technology demonstration program update 1995. DOE Contract No: DOE/FE-0346 (1996)

U.S. DOE: ENCOAL mild gasification project. DOE Contract No: DEFC21-90MC27339 (1997)

Yanagi, K., Okuma, O., Shigehisa, T., Deguchi, T.: U.S. Patent 5,556,436, registered in 1996, filed in 1994

Yosumuro, M., Deguchi, T., Shigehisa, T., Shimasaki, K.: In: Proceedings of Prospects for Coal Sci. in the 21st Century, pp. 175-179 (2000) 